\title{
BAMBOO FOUNDATION \\ Dengan Pendekatan Sustainable Architecture Di BOYOLALI
}

\author{
Adi Surya Kusumo, Titis Srimuda Pitana, Made Suastika \\ Program Studi Arsitektur \\ Fakultas Teknik \\ Universitas Sebelas Maret Surakarta \\ Email : suryakusumo@gmail.com
}

\begin{abstract}
The background of designing Bamboo Foundation in Boyolali is the emergence of human's awareness to save the environment especially in the use of eco-friendly building materials. Unfortunately these phenomenon is used by several parties to gain much profit by producing materials and labeling their product with eco-friendly label and then sell them in a very expensive price. Because of the phenomenon then occur an idea to persuade the society to use eco-friendly materials but in a cheap price and good quality which is bamboo. Along with the finding of bamboo preservation and processing methods, it shows that bamboo has a big potential to be used as main material in a construction. So the existence of Bamboo Foundation to provide education about bamboo for the society. The designing problem is not only how to develop the bamboo preservatives and processing education but also about the conservation of various bamboo species based on the application of sustainable architecture in Bamboo Foundation design. The method used is architectural design method that combine various bamboo construction structure with the application of sustainability architecture. The result is the design of a bamboo education facilities consists of gallery, class, workshop, bamboo conservation, and supporting buildings that also use as a precedent for the visitors.
\end{abstract}

Keywords: Bamboo, Conservation, Education, Sustainable Architecture.

\section{PENDAHULUAN}

Manusia seakan tak ada habisnya mengeksploitasi alam dari segala bidang yang mereka geluti, tak terkecuali pada bidang pembangunan. Kerusakan alam yang terjadi kemudian memunculkan kesadaran bagi masyarakat untuk mulai menggunakan material bangunan yang ramah lingkungan untuk membantu menyelamatkan bumi.

Fenomena ini ternyata memberikan kesempatan bagi beberapa pihak tertentu untuk memanfaatkan peluang ini hanya untuk mendapatkan keuntungan dengan cara memberi label green, ekologis, atau simbolsimbol ramah lingkungan lainnya dan kemudian menjualnya dengan harga jauh lebih tinggi. Hal ini mengundang anggapan bahwa masyarakat hanya bisa menyelamatkan bumi dengan harga yang mahal. Padahal sebenarnya masyarakat juga bisa ikut andil dalam menyelamatkan lingkungan dengan memanfaatkan bahan material bangunan disekitar mereka asalkan dengan cara yang benar.
Salah satu material alam lokal yang murah dan banyak ditemui di sekitar kita adalah bambu. Setelah diteliti ternyata bambu juga memiliki banyak sekali potensi dan kelebihan asalkan dimanfaatkan secara benar. Hadir dengan kemampuannya untuk dengan cepat bertumbuh dan diperbaharui, bambu menjadi salah satu ikon nyata konsep sustainability yang dapat terus menerus berkelanjutan meskipun digunakan dalam jumlah yang besar.

Penemuan tentang metode pengawetan dan pengolahan bambu secara modern saat ini belum banyak diketahui oleh masyarakat, sehingga perlu adanya sebuah wadah untuk mengedukasi masyarakat tentang bambu yaitu Bamboo Foundation. "Bamboo Foundation merupakan sebuah wadah bagi yayasan yang secara intensif mengenalkan bambu sebagai bahan bangunan di masa depan dan sekaligus melakukan upaya konservasi pelestarian tanaman bambu" (Widnyana, 2009). Dengan adanya fasilitas ini diharapkan mulai memunculkan anggapan masyarakat bahwa 
bambu juga bisa menjadi pilihan utama untuk dijadikan material bangunan yang ramah lingkungan. Kompleks bangunan Bamboo Foundation yang direncanakan terdiri atas bangunan galeri karya bambu, kelas, ruang workshop, lahan konservasi bambu, dan beberapa bangunan penunjang yang kesemuanya akan menggunakan aplikasi sistem struktur bambu yang bermacammacam, sehingga dapat sekaligus menjadi preseden dan sumber inspirasi bagi para pengunjung yang datang.

\section{METODE}

A. Membangun Gagasan dari Fenomena Penentuan gagasan awal yang mendasari alasan berdirinya bangunan Bamboo Foundation berawal dari munculnya fenomena meningkatnya kesadaran masyarakat yang untuk menjaga kelestarian alam salah satunya dengan menggunakan material bangunan yang ramah lingkungan. Namun karena adanya pemanfaatan oleh berbagai pihak untuk mengambil keuntungan dari gerakan ini, maka lahirlah gagasan untuk mengedukasi masyarakat agar tetap dapat menggunakan material ramah lingkungan yang murah dan juga mudah diperbaharui yaitu bambu. "Material yang sustainable memiliki konsekuensi besar dalam hal pengadaan, penanganan, dan cara pemanfaatannya, serta kepedulian terhadap detail dan pelestariannya" (Halliday, 2008). Seperti yang dikatakan kutipan tersebut untuk memanfaatkan material yang sustainable seperti bambu maka diperlukan konsekuensi besar dalam memulainya. Oleh karena itu, untuk memberikan fasilitas bagi masyarakat yang ingin mengetahui dan mempelajari tentang bambu beserta pemanfaatannya maka dibutuhkan fasilitas berupa Bamboo Foundation.

B. Penerapan Strategi Desain

Setelah mendapatkan intisari dari tema yang digunakan maka langkah selanjutnya adalah menguraikan aplikasi prinsip-prinsip Sustainable Architecture menjadi sebuah strategi desain dalam perancangan. (Williams, 2007) menjelaskan beberapa prinsip dalam Sustainable Architecture yang sebenarnya harus dilakukan dalam setiap desain bangunan di masa sekarang, sebagai berikut.

1. Efisiensi pengunaan energi dan air, serta meminimalisir penggunaan energi yang tidak terbarukan.

2. Efisiensi penggunaan lahan dengan bijak.

3. Manajemen limbah untuk dimanfaatkan kembali atau diolah sebelum dikembalikan ke lingkungan.

4. Efisiensi penggunaan material yang bermanfaat dan berumur panjang (lebih panjang dari siklus hidupya).

5. Penggunaan teknologi dan material baru.

\section{ANALISIS}

\section{A. Analisis Peruangan}

1. Tujuan

Untuk memperoleh kebutuhan ruang yang diperlukan berdasarkan kegiatan yang dilakukan dalam Bamboo Foundation di Simo, Boyolali.

2. Dasar Pertimbangan

a. Kegiatan yang dilakukan pelaku menjadi dasar penentuan ruangruang yang harus bisa mengakomodir berbagai kegiatan tersebut.

b. Penyusunan peruangan juga harus memperhatikan keterkaitan antar satu ruang dengan yang lain agar suatu bangunan dapat berfungsi secara maksimal.

Analisis kebutuhan ruang disajikan bersama berbagai macam jenis pelaku yang ada di dalam Bamboo Foundation, apa saja kegiatan yang dilakukan di dalamnya, serta ruanganruangan apa sajakah yang diperlukan untuk diaplikasikan dalam desain kompleks bangunan Bamboo Foundation.(lihat Tabel 1)

Tabel 1.Kebutuhan Ruang

\begin{tabular}{|l|l|l|}
\hline $\begin{array}{l}\text { Jenis } \\
\text { Pelaku }\end{array}$ & Kegiatan & $\begin{array}{l}\text { Kebutuhan } \\
\text { Ruang }\end{array}$ \\
\hline
\end{tabular}




\begin{tabular}{|c|c|c|}
\hline \multirow{12}{*}{$\begin{array}{l}\text { Kegiatan } \\
\text { Pengun- } \\
\text { jung } \\
\text { Reguler }\end{array}$} & Parkir & Tempat Parkir \\
\hline & Mendaftar & R. Penerima \\
\hline & $\begin{array}{l}\text { Melihat } \\
\text { Preseden }\end{array}$ & $\begin{array}{l}\text { Galeri Karya } \\
\text { Bambu }\end{array}$ \\
\hline & $\begin{array}{l}\text { Mendapat } \\
\text { Materi Teori }\end{array}$ & $\begin{array}{l}\text { Kelas Materi } \\
\text { Bambu }\end{array}$ \\
\hline & Workshop & R. Workshop \\
\hline & Pengawetan & Pengawetan \\
\hline & $\begin{array}{l}\text { Workshop } \\
\text { Pengolahan }\end{array}$ & $\begin{array}{l}\text { R. Workshop } \\
\text { Penoolahan }\end{array}$ \\
\hline & Mengamati & Lahan \\
\hline & Bambu & Konservasi \\
\hline & $\begin{array}{l}\text { Makan dan } \\
\text { Bersantai }\end{array}$ & Foodcourt \\
\hline & Beribadah & Masjid \\
\hline & $\begin{array}{l}\text { Menonton } \\
\text { Pertunjukan }\end{array}$ & Amphitheatre \\
\hline \multirow{5}{*}{$\begin{array}{l}\text { Kegiatan } \\
\text { Peneliti }\end{array}$} & $\begin{array}{l}\text { Berdiskusi dan } \\
\text { Meneliti }\end{array}$ & $\begin{array}{l}\text { R. Riset dan } \\
\text { Diskusi }\end{array}$ \\
\hline & $\begin{array}{l}\text { Praktek Hasil } \\
\text { Penelitian }\end{array}$ & $\begin{array}{l}\text { R. Workshop } \\
\text { Pengolahan }\end{array}$ \\
\hline & Meneliti & Lahan \\
\hline & Bambu & Konservasi \\
\hline & Beristirahat & Penginapan \\
\hline \multirow{3}{*}{$\begin{array}{l}\text { Kegiatan } \\
\text { Klien }\end{array}$} & $\begin{array}{l}\text { Melihat } \\
\text { Referensi }\end{array}$ & $\begin{array}{l}\text { Galeri Karya } \\
\text { Bambu }\end{array}$ \\
\hline & $\begin{array}{l}\text { Berkonsultasi } \\
\text { dengan Ahli }\end{array}$ & $\begin{array}{l}\text { Ruang } \\
\text { Konsultasi }\end{array}$ \\
\hline & $\begin{array}{l}\text { Mengamati } \\
\text { Konstruksi }\end{array}$ & $\begin{array}{l}\text { R.Workshop } \\
\text { Pengolahan }\end{array}$ \\
\hline \multirow{3}{*}{$\begin{array}{l}\text { Kegiatan } \\
\text { Pembina } \\
\& \\
\text { Pengawas }\end{array}$} & Bekerja & R. Pembina \\
\hline & Bekerja & R. Pengawas \\
\hline & Rapat & Ruang Rapat \\
\hline
\end{tabular}

B. Analisis Lokasi

Pemilihan lokasi dilakukan dengan membandingkan dua lokasi yang dianggap berpotensi lalu menilai kelebihan dan kekurangannya masing-masing.

1. Tujuan

Untuk memperoleh lokasi tapak yang direncanakan untuk bangunan Bamboo Foundation di Simo, Boyolali.

2. Dasar pertimbangan

a. Tapak memiliki luasan yang cukup besar untuk menampung semua bangunan dan kegiatan yang berlangsung dalam kompleks bangunan Bamboo Foundation.

b. Tapak yang dibutuhkan adalah yang dekat dengan sumber daya alam berupa hutan bambu untuk kebutuhan operasional Bamboo Foundation.

c. Tapak harus dekat dengan permukiman warga, khususnya para pengrajin bambu yang nantinya juga akan menjadi pengelola Bamboo Foundation.

d. Tapak terletak di dekat sungai sebagai sumber pengairan bagi konservasi bambu.

e. Tapak yang dipilih hendaknya masih asri keadaan alamnya dan memiliki temperatur yang sejuk dan nyaman untuk pertumbuhan bambu.

\section{Analisis Pencapaian}

Pencapaian ke dalam bangunan harus berhubungan langsung dengan jalan yang mudah diakses oleh para pengunjung.

1. Tujuan

menentukan main entrance, menentukan side entrance

2. Dasar Pertimbangan

Jalan memiliki tanah yang cukup lapang dan mudah dicapai untuk main entrance, side entrance, dan area parkir pengunjung kompleks bangunan Bamboo Foundation.

3. Proses analisis

Pencapaian menuju ke bangunan menggunakan kendaraan bermotor dominan berasal dari jalan utama yang terletak di sebelah barat laut dari tapak. Melalui analisis ini, maka main entrance (ME) diletakkan di bagian tenggara yang berdekatan dengan sungai, hal ini dikarenakan perancang ingin mempersilahkan para pengunjung menikmati tampilan luar kompleks bangunan ini sebelum akhirnya memasukinya di ujung jalan. Di bagian samping ME ini nantinya akan disediakan jalur side entrance (SE) bagi pengelola yang akan membawa material bambu dari lahan konservasi yang direncanakan berada di sebelah 
timur laut dari tapak (lihat Gambar $1)$.

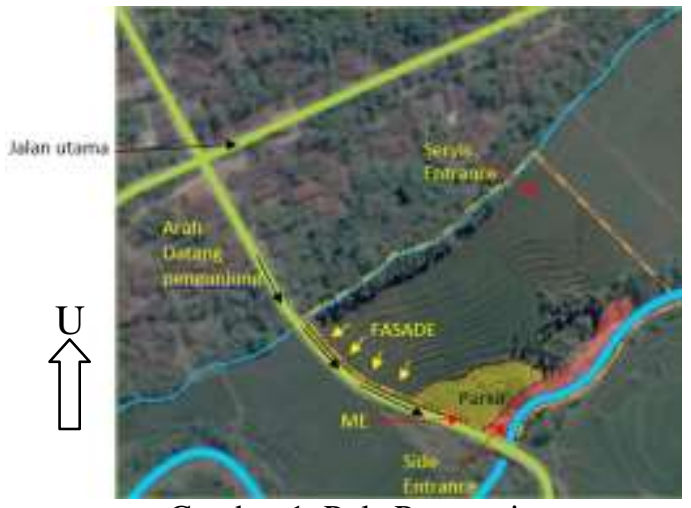

Gambar 1. Pola Pencapaian.

D. Analisis Iklim dan Lingkungan

1. Tujuan

Untuk mengetahui kondisi iklim dan lingkungan sekitar tapak, serta menentukan respon yang tepat untuk menyesuaikan bangunan yang akan direncanakan dengan kondisi sekitar sesuai dengan prinsip Sustainable Architecture.

2. Dasar pertimbangan

a. Menerapkan penggunaan lahan secara efisien dengan sebisa mungkin memberikan dampak positif terhadap lingkungan dan tidak merusak keseimbangan lingkungan.

b. Memanfaatkan kondisi lahan yang berkontur dengan meminimalisir pengolahan cut and fill.

c. Menyesuaikan arah orientasi dan desain bangunan agar dapat memaksimalkan penghawaan dan pencahayaan alami dari sinar matahari dan angin yang melewati tapak.

3. Proses analisis

Bangunan akan diletakkan dengan orientasi bangunan menghadap ke timur, dengan pemberian penghalang sinar matahari sore berupa lahan bambu di bagian barat. Selain itu, pemanfaatan cahaya matahari juga dilakukan yaitu dengan memasukkan cahaya matahari pagi lewat bukaan samping dan juga memanfaatkan sinar matahari siang yang telah direduksi dengan bahan anti sinar UV pada bagian skylight. Untuk merespon tapak yang berkontur maka bangunan akan didesain mengikuti bentuk kontur atau menggunakan bentuk panggung untuk meminimalisir cut and fill (lihat Gambar 2).

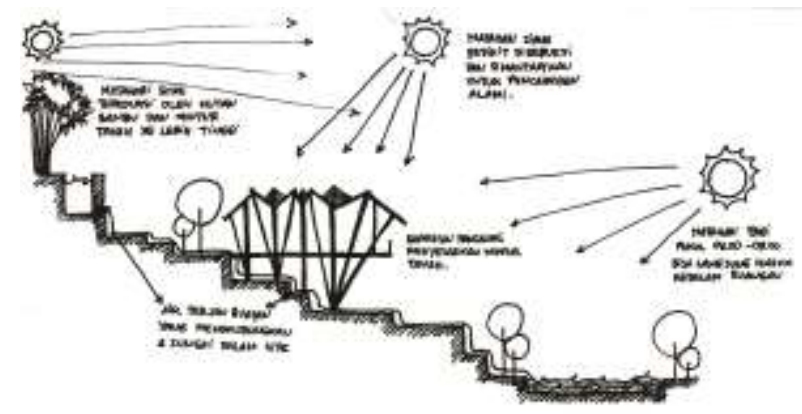

Gambar 2. Analisis Respon Terhadap Iklim dan Lingkungan.

E. Analisis Bentuk dan Gubahan Massa

1. Tujuan Untuk memperoleh konsep bentuk gubahan massa yang akan digunakan pada bangunan agar sesuai dengan lingkungan sekitar.

2. Dasar Pertimbangan

a. Bentuk dan gubahan massa bangunan harus menyesuaikan dengan kontur lahan yang melengkung.

b. Bentuk bangunan harus merepresentasikan berbagai bentuk konstruksi bangunan bambu guna memberikan contoh langsung pada para pengunjung.

3. Proses analisis Dalam penentuan bentuk bangunan harus dioptimalkan bentuk yang efisien sehingga memudahkan sirkulasi dan kegiatan dalam bangunan. Menurut Ching (1979) bentuk yang efisien dapat terdiri dari dua bentuk dasar (lihat pada Tabel 2).

Tabel 2. Karakteristik Bentuk Dasar.

\begin{tabular}{|l|l|}
\hline $\begin{array}{l}\text { Bentuk } \\
\text { Dasar }\end{array}$ & Karakteristik \\
\hline
\end{tabular}




\begin{tabular}{|c|c|}
\hline segi empat & $\begin{array}{l}\text { - Karakter bentuk netral, } \\
\text { statis, formal, solid } \\
\text { - Efisiensi pemakaian } \\
\text { ruang dan fungsi } \\
\text { - Kemudahan dalam } \\
\text { pengerjaan struktur } \\
\text { - Mudah melakukan } \\
\text { pengembangan bentuk } \\
\text { dasar }\end{array}$ \\
\hline & $\begin{array}{l}\text { - Mempunyai kekuatan } \\
\text { visual yang maksimal } \\
\text { - Mempunyai sudut } \\
\text { pandang ke segala arah } \\
\text { - Kemudahan untuk } \\
\text { pengolahan sirkulasi } \\
\text { - Dengan pengembangkan } \\
\text { akan menimbulkan gerak } \\
\text { lingkarang dinamis. }\end{array}$ \\
\hline
\end{tabular}

Kondisi tapak yang berkontur dan berbentuk melengkung harus direspon dengan bentuk bangunan yang menyesuaikan bentuk kontur tanah agar sesuai dan enak dipandang. Bentuk alam yang melengkung memberikan inspirasi tersendiri dalam mengekpresikan gubahan massa pada bangunan Bamboo Foundation (lihat Gambar 3).

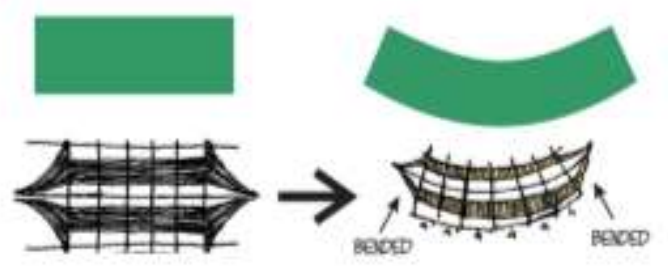

Gambar 3. Bentuk Bangunan Mengikuti Bentuk Lahan yang Melengkung.

Bentuk tapak yang berkontur juga direspon dengan bentuk-bentuk bangunan panggung (lihat Gambar 4). Massa ini digunakan untuk memperoleh bentuk lantai yang datar tanpa merubah bentuk asli dari tapak dan juga dapat menambah resapan air hujan sehingga keasrian lingkungan tetap terjaga.

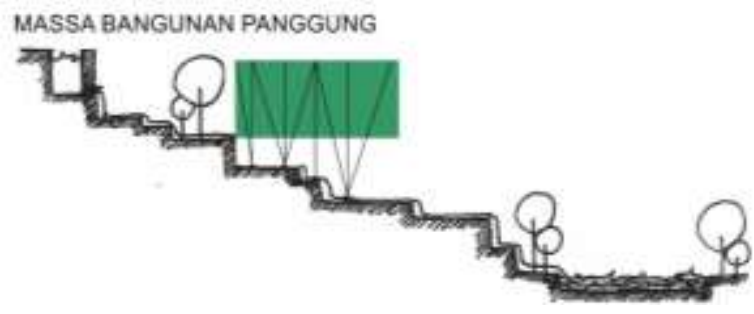

Gambar 4. Bentuk Bangunan Panggung.

Selain itu, untuk mempertahankan bentuk tanah yang berkontur maka akan digunakan bentuk massa bangunan yang menyesuaikan bentuk tanah yang berkontur (lihat Gambar 5). Massa ini dapat memberikan efek bentuk yang dinamis pada bangunan. Selain itu juga memudahkan pengolahan struktur pada bangunan.

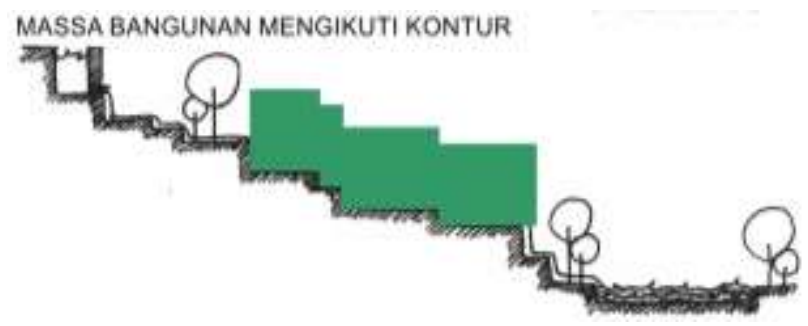

Gambar 5. Bentuk Bangunan Mengikuti

Ketinggian Kontur Tapak.

Ketiga tipe bentuk tersebut akan diaplikasikan secara terpadu dalam bangunan-bangunan Bamboo Foundation.

F. Analisis Material dan Bahan

1. Tujuan

Untuk memperoleh analisis penggunaan material pada bangunan agar sesuai dengan prinsip Sustainable Architecture.

2. Dasar pertimbangan

Material harus ramah lingkungan mulai dari pengadaan, pengiriman, hingga pengolahannya. Material yang digunakan dalam bangunan ini harus dapat diperbaharui atau dipergunakan kembali sesuai dengan prinsip Sustainable Architecture.

3. Proses analisis 
Pendekatan

Architecture

Sustainable

mengharuskan

Bamboo Foundation menggunakan material yang ramah lingkungan dan sustainable sebagai berikut. (lihat Gambar 6)

\section{a. Bambu}

Bambu dikenal sebagai bahan bangunan yang sangat mudah diperbaharui karena siklus hidupnya yang sangat cepat yaitu tiga tahun hingga massa panen. Selain itu bambu juga memiliki kekuatan daya rentang yang lebih kuat dibandingkan dengan baja. Bambu juga merupakan material alami sehingga sisa penggunaanya tidak akan mencemari lingkungan.

b. Kayu Bekas

Menggunakan kembali kayukayu bekas bongkaran bangunan lama menjadi salah satu alternatif dalam menjaga kelestarian hutan dengan mengoptimalkan penggunaan kayu. Hal ini tentu saja sejalan dengan pendekatan yang digunakan yaitu Sustainable Architecture yang ingin menjaga keberlangsungan kehidupan.

c. Kaca

Untuk keperluan bukaan ruang diperlukan material kaca untuk memasukkan pencahayaan alami kedalam bangunan. Pemanfaatan pencahayaan alami juga merupakan upaya penghematan energi untuk mendukung prinsip Sustainable Architecture.

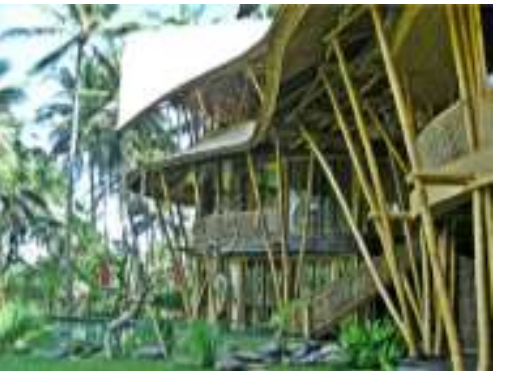

Gambar 6. Penggunaan Material Bambu, Kayu Bekas, dan Kaca pada Bangunan.

(sumber: www.archdaily.com, 2015)

G. Analisis Struktur Bangunan

1. Tujuan

Memperoleh struktur yang tepat pada bangunan Bamboo

Foundation khususnya pada struktur bambu yang digunakan.

2. Dasar Pertimbangan

Kondisi lahan yang berkontur sangat berpengaruh pada pemilihan sistem struktur bangunan. Sistem konstruksi bambu yang digunakan dalam bangunan ini adalah sistem konstruksi tradisional dengan sistem knockdown.

3. Proses analisis

Bangunan ini akan dominan menggunakan struktur bambu. Sebelum digunakan bambu terlebih dahulu akan diberikan treatment upaya pengawetan agar bambu tahan lama. Untuk menanggulangi permasalahan serangga bubuk dan air, ada tiga jenis metode pengawetan yang akan digunakan yaitu adalah dengan metode perendaman, dengan cara kimiawi yaitu dengan pemberian cairan boraks pada batang bambu yang masih utuh, dan terakhir pengawetan pada tahap finishing yaitu dilakukan proses coating untuk melapisi pori-pori luar dari bambu.

a. Sub structure (Pondasi)

Sistem pertama yang dapat digunakan adalah sistem pondasi titik dengan umpak yang dapat mengikuti kontur dengan ketinggian yang berbeda-beda sehingga keaslian 
kontur akan tetap terjaga (lihat Gambar 7).

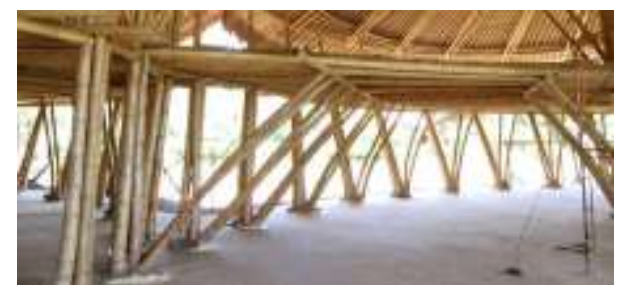

Gambar 7. Preseden Penggunaan Pondasi Umpak pada Bangunan Bambu.

(sumber: www.archdaily.com, 2015)

Khusus untuk bagian struktur pondasi untuk sebaiknya tidak disarankan melakukan penanaman bambu ke dalam tanah karena menyebabkan peresapan air dari tanah yang dapat merusak struktur alami bambu. Cara lain yang dapat dilakukan adalah dengan menyambungkan dasar bambu dengan plat baja yang kemudian diteruskan dengan penanaman baja dalam pondasi beton dalam tanah (lihat Gambar 8).

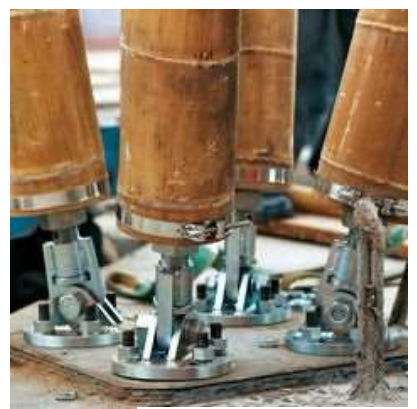

Gambar 8. Pondasi Bambu dengan

Penanaman Baja dalam Beton.

(sumber: www.picsora.com, 2015)

\section{b. Supper structure (Badan)}

Pada bagian ini akan digunakan inovasi pemanfaatan bambu sebagai struktur utama bangunan sebagai berikut.

1) Plastered Bamboo Wall adalah sebuah inovasi pengolahan bambu untuk dijadikan material subtitusi dari batu bata yang dikenal tidak dapat dipebaharui. Jalinan bilah bambu yang dilapisi plesteran semen ini dapat menghasilkan dimensi dinding yang lebih tipis yaitu hanya sekitar delapan sentimeter dan tentunya dengan kekuatan yang setara dengan dinding bata (lihat Gambar 9). Dengan penggunaan teknologi ini diharapkan akan mengurangi sampah sisa pembangunan yang sulit diuraikan kembali oleh tanah.

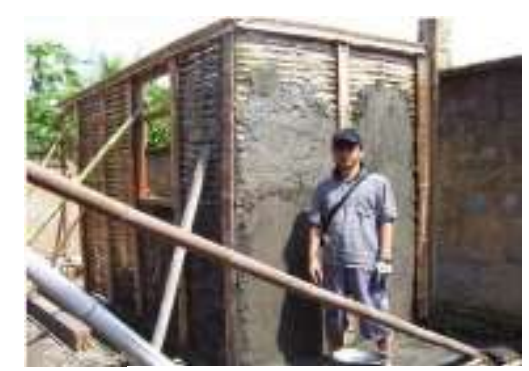

Gambar 9. Aplikasi Bambu yang Diplester.

(sumber: Dokumen Faisal, 2012)

2) Konstruksi bambu sebagai substitusi dari rangka baja plat lantai beton.

Dengan kekuatan yang dimiliki bambu, ternyata bambu juga dapat digunakan untuk pengganti wiremesh pada plat lantai beton sehingga plat lantai menjadi lebih ringan dan mengurangi pembebanan pada struktur di bawahnya (lihat Gambar 10).

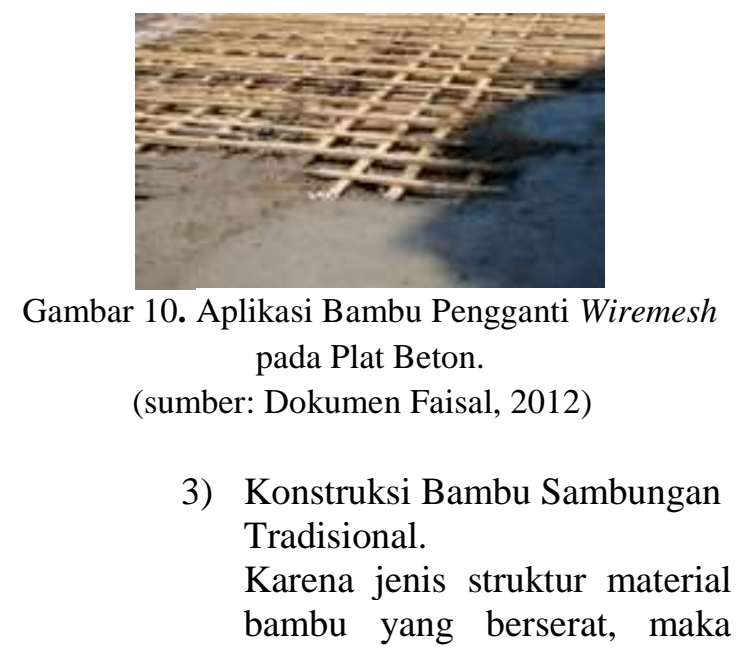


bambu sangat tidak cocok jika menggunakan sambungan berupa paku karena akan merusak serat dan akhirnya dapat membelah bambu itu sendiri. Oleh karena itulah dari jaman dahulu masyarakat Indonesia menggunakan sambungan tradisional dengan menggunakan pasak yang terbuat dari bambu juga (lihat Gambar 11). Meskipun dianggap tradisional, namun sistem sambungan ini dianggap paling kuat untuk kontruksi bambu hingga saat ini.

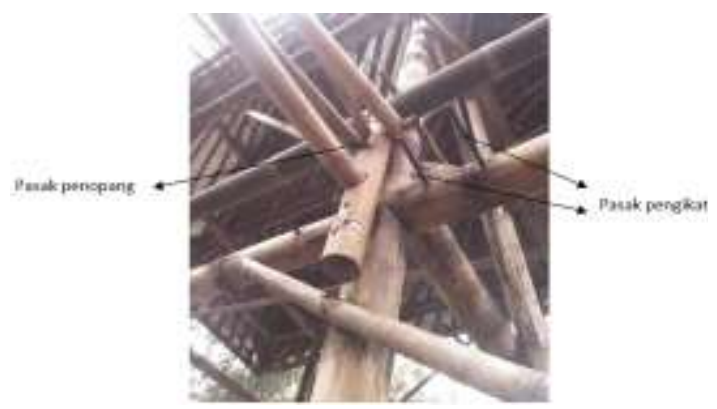

Gambar 11. Aplikasi Sambungan Pasak Bambu.

\section{c. Upper structure}

Ada beberapa macam aplikasi struktur bambu pada bagian pembalokan rangka atap. Untuk aplikasi pada bangunan-bangunan dengan bentuk yang melengkung atau organik dapat menggunakan prinsip struktur lidi beam, bundle beam, maupun split beam (lihat Gambar 12)
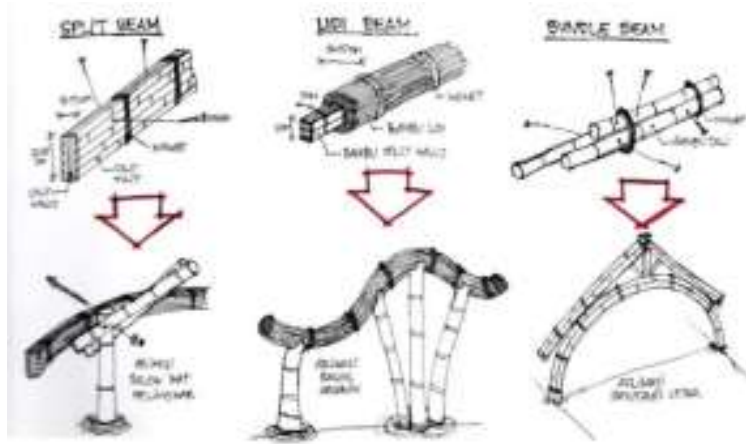

Gambar 12. Sistem Struktur Pembalokan Rangka Atap Konstruksi Bambu Struktur Organik atau Melengkung.

(sumber: Dokumen Adhiwira, 2013)

\section{KESIMPULAN (KONSEP DESAIN)}

Konsep rancangan Bamboo Foundation mengacu pada pengaplikasian materialmaterial yang ramah lingkungan dan juga sustainable khususnya bambu. Selain itu pengenalan konsep inovasi pada pengolahan bambu (lihat Gambar 13) dapat menstimulus para pengunjung untuk datang dan mempelajari cara pengawetan dan pengolahan bambu sekaligus cara melestarikannya. Dari analisis serta hasil kolerasi dari beberapa di atas, maka diperoleh hasil berupa rancangan Bamboo Foundation di Boyolali dengan Pendekatan Sustainable Architecture sebagai berikut (lihat Gambar 14 \& 15).

Nama Bangunan : Bamboo Foundation

Lokasi

: Desa Walen, Kecamatan

Luas Lahan $\quad: 15.000 \mathrm{~m}^{2}$

Luas Bangunan : $2.900 \mathrm{~m}^{2}$

Kegiatan : Edukasi, Konservasi, dan Konstruksi bambu.

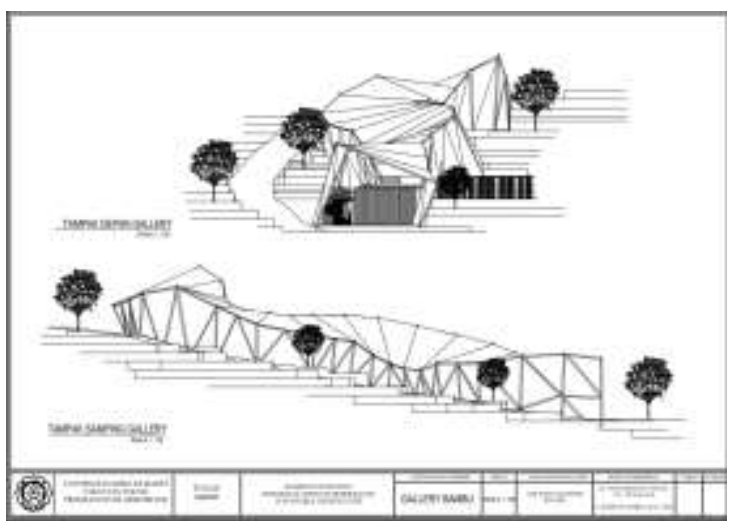

Gambar 14. Tampak Galeri Bambu

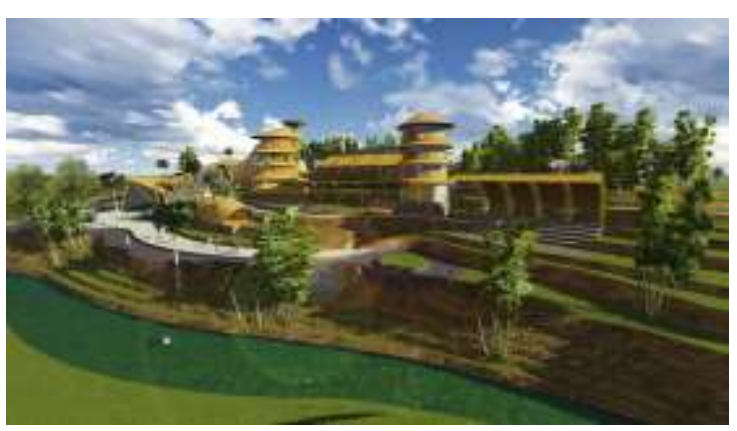

Gambar 15. Perspektif Eksterior 


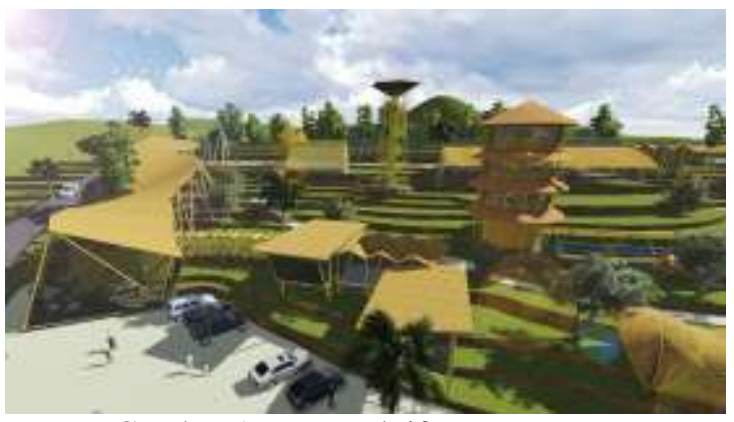

Gambar 16. Perspektif Mata Burung

\section{REFERENSI}

Adhiwira, Effan. 2013. Seminar Merajut Bambu Seribu Candi.

Ching, Francis D. K. 1979. Architecture:

Form, Space, and Order. USA: Wiley.

Faisal, Budi. 2012. Rubrik Bale. Koran Suara Merdeka.

Halliday, Sandy. 2008. Sustainable Construction. Oxford: Elsevier.

Widnyana, K. 2009. Bambu dengan Berbagai Manfaatnya. Bumi Lestari Journal of Environment Vol 8.

Williams, Daniel E. 2007. Sustainable Design: Ecology, Architecture, and Planning. New Jersey: John Wiley \& Sons.

www.archdaily.com

www.picsora.com 